\title{
Mathematical Criteria for Stability of NPA growth Improving Quality of Service for Banks
}

\author{
Jaya Shukla ${ }^{1}$ and Gaurav Bajpai ${ }^{2}$ Member, IACSIT
}

\begin{abstract}
This paper presents a mathematical model for problem of stability of non- performing assets (NPA's) growth in banking sector. The various variables leading to high NPA are identified. A sufficient criterion which ensures the damping out of the effects arising out of the perturbations in the variables is obtained. The model assumes prevalence of normal conditions in banking sector in terms of liquidity, political interference and other external factors affecting the stability of NPA. The model emphasizes on growth of NPA's at stable rate to improve banks asset portfolio and quality of service assured by banks.
\end{abstract}

Index Terms-NPA(non- performing assets), QoS (Quality of Service)

\section{INTRODUCTION}

NPA is defined as an advance for which interest or repayment of principal or both remain outstanding for a period of more than two quarters [1]. The level of NPA acts as an indicator showing the banker's credit risks and efficiency of allocation of resource. NPA'S are assets that are classified into three categories [2].

Sub-standard assets: These are assets which had been NPA for a period of less then 12 months.

1) Doubtful assets: These are assets which remained as NPA for period exceeding 12 months.

2) Loss assets: These are NPA which are identified as unreliable by internal inspector of bank or auditors or by RBI.

The reasons for NPA's are classified into two components; the first is Overhang component that is due to environment reasons, business cycle etc. while the second is Incremental component which is due to internal bank management, credit policy, terms of credit etc. In this paper Incremental components have been dealt as different parameters of interest while the external components are principally ignored here.

\section{Formulation OF PROBLEM}

Global integration of financial sector need banks to be more competitive as high NPA growth degrades the credit position of banks affecting their performing ability. Every country needs to meet the goal of the development so zero level of NPA'S is difficult task to achieve. Studies have shown that management of NPA'S rather than elimination is prudent. Developing countries like India with high growth rate can support non zero level of NPA's which balances the risk with return appropriate to Indian context [3]. There is some stable rate of NPA growth which a country can afford without affecting banks competitive efficiency. This stable rate will not only restore banks competitive ability but also improve its quality of service.

Increasing NPA's are pressure on banks as it affects banks ability to provide credit which itself depends upon total creditable surplus with bank and number of client to whom it is providing credit. Bank in order to earn more profit try to provide more credit that further increases the possibility of growth of NPA's. High NPA'S often bring big crisis for the banking system and thus for the whole country. The same happened in South-East Asian countries banking crisis [4].

Under normal conditions generally borrowers of banks are responsible for making performing asset into non performing indirectly affecting banks quality of service. Sometimes high NPA of bank creates situation to bankruptcy or lead to merger and closure of it. Here this is only solution to the problem but we assume unseen tribulations at banks end and this assumption is made to ensure continuity of whole process for stability of NPA'S.

We define growth of NPA'S as a ratio of creditable surplus $\mathbf{B}_{\mathbf{i}}$ of bank to weighted index $\mathbf{w}_{\mathbf{i}}$ for i number of clients where $\mathbf{p}_{\mathbf{i}}$ is pressure on the bank that is dependent on ability to provide credit at a specific time.

$$
\mathrm{p}_{\mathrm{i}}=\mathrm{B}_{\mathrm{i}} / \mathrm{w}_{\mathrm{i}}
$$

Since $B_{i}$ and $w_{i}$ may vary with time $p_{i}$ is function of time under conditions theoretically pi should be same for all person.

This can be ensured in two ways:

1) keep $B_{i}$ same for all persons and similarly $w_{i}$

2) Restrict the need of $w_{i}$ for credit in such a way that the ratio of $B_{i} / w_{i}$ remain same for all banks.

The first case is made feasible if bank itself controls decision of credit distribution irrespective of the purpose for which credit is taken, nature of their work and capacity to utilize the credit.

The needs for which loans are divided into two categories:-

1) Basic necessities like housing, durable goods, etc.

2) Special needs depending upon nature of one's profession, business like business, education, infrastructure etc.

The later are met by bank in kind while former are met by users against their income as security. To keep $\mathrm{B}_{\mathrm{i}}$ same for all persons, it will restrict the bank to provide security, stability and compensation etc. through assurance of quality of service under this case.

In second case that generally exist central bank provide guidelines and criteria for credit distribution to be followed by banks to different clients and ensure reuse of the same 
creditable surplus. Such distribution of credit is priority based keeping in account the development needs of the country.

Since, there exists difference in credit distribution we need to define average or collective credit distribution.

Let $\mathrm{n}(\mathrm{x})$ be the no. of clients whose credit amount is less than equal to $\mathrm{x}$ at that time and $\mathrm{N}$ be the total number of clients. The collective credit distribution $\mathrm{p}_{\mathrm{ccd}}$ can be defined as

$$
\mathrm{p}_{\mathrm{h}}-\mathrm{p}_{\mathrm{ccd}}=\{1 / \mathrm{N}\} \int_{0}^{\mathrm{p}_{\mathrm{h}}} \mathrm{n}(\mathrm{x}) \mathrm{dx}
$$

If credit distribution is same for all borrowers, assume $p$ the above definition shows $p_{c c d}=p$, since $n(x)=N$ for $x=p$ there being only one class.

Actually in terms of individual credit availability, the borrowers can be divided into equivalence classes, these class differences may manifest themselves by exerting pressure over banks etc. to act and ensure proper measure of this quality of service for this pressure.

If $\mathrm{p}_{1}$ and $\mathrm{p}_{\mathrm{h}}$ be pressure generated by credit availability to poorest or richest people at time t. Divide the spread $p_{h}-p_{1}$ by $\mathrm{p}_{\mathrm{ccd}}$ and take greatest integer in $\left\{\left(\mathrm{p}_{\mathrm{h}}-\mathrm{p}_{\mathrm{l}}\right) / \mathrm{p}_{\mathrm{ccd}}\right\}$ if not an integer. In either case add 1 and denote figure by $\mathrm{M}$. Now divide the interval $(0, p)$ into $M$ equal parts by partition $0<p_{1}$ $<\mathrm{p}_{2}<\ldots<\mathrm{p}_{\mathrm{m}}=\mathrm{p}_{\mathrm{h}}$

The pressure $\mathrm{P}$ at time $\mathrm{t}$ is defined as

$$
\mathrm{P}=\sum_{\mathrm{k}=1}^{\mathrm{M}} \mathrm{n}_{\mathrm{k}} / \mathrm{p}_{\mathrm{k}}
$$

Where $n_{k}$ is the number of clients whose credit availability is such that $\mathrm{p}_{\mathrm{k}-1}<\mathrm{p} \leq \mathrm{p}_{\mathrm{k}}$,

$\mathrm{k}=1,2 \ldots, \mathrm{m}$ with $\mathrm{p}_{\mathrm{k}-1}$ being taken zero for $\mathrm{k}=1$.

This definition of pressure implies that if majority of clients of bank belong to small loan category $\mathrm{P}$ will be large. (i.e. low credit taking people and high influx)

If the majority of clients of financial institution are those who take big loans pressure $\mathrm{P}$ will be smaller on bank or financial institution. (i.e. high credit taking people and low density).

If the loans provided to clients have no class differences the credit distribution will be same for all clients hence $\mathrm{p}_{\mathrm{h}}-\mathrm{p}_{\mathrm{l}}$ $=0$ and we have one partition $(0, p), p$ being common credit density. In this case formula for pressure $\mathrm{P}$ becomes

$$
\mathrm{P}=\mathrm{N} / \mathrm{p}
$$

The changes in pressure prompt, financial institution to realize suitable measures for proper activity of bank since, its activity requires expenditure depending upon the quantum of credit at any time $t$.

Thus, if we denote $\mathrm{q}$ the collection of loans recovered by bank at time $t$, this quantity of fund would provide measure for bank's further activity.

The state of financial institution at any time $\mathrm{t}$ is characterized by variables $\mathrm{P}, \mathrm{q}, \mathrm{p}_{\mathrm{ccd}}$ which is function of time.

We shall deem a financial institution activity to be static if $\mathrm{q}$ remains constant and call it dynamic if $\mathrm{q}$ continues to change with reference to time.
The implication of this is that for a dynamic q, to meet the change in pressure $p$ and in $q$ should bring about a change in collective credit distribution. Thus if $\mathrm{p}_{0}, \mathrm{q}_{0}, \mathrm{p}_{\mathrm{ccd} 0}$ be the reference values at any time $t=t_{0}$ of the pressure, activity of the financial institution, collective credit distribution respectively then the following could be plausible relations between $\mathrm{P}, \mathrm{q}, \mathrm{p}_{\mathrm{ccd}}$

$$
\mathrm{q}-\mathrm{q}_{0}=\alpha\left(\mathrm{P}-\mathrm{P}_{0}\right)
$$

$\mathrm{p}_{\mathrm{ccd}}-\mathrm{p}_{\mathrm{ccd} 0}=\mathrm{A}\left(\mathrm{q}-\mathrm{q}_{0}\right)+\mathrm{B}\left(\mathrm{q}-\mathrm{q}_{0}\right)^{2}+\mathrm{C}\left(\mathrm{q}-\mathrm{q}_{0}\right)^{3}+\ldots$ etc.

Here $\alpha$ is taken to be a positive constant denoting the coefficient of earning of financial institution as a profit situation $(\alpha>0)$.

$\alpha$ is assumed to be constant since the activity of the financial institution with existing resources are not expected to change rapidly.

The constants A, B, C...etc are parameters analogous to the financial characteristics.

A financial institution becomes unstable if the arbitrary perturbations in pressure, collective credit distribution and financial institution activity get magnified with the lapse in time i.e. perturbations go out of control.

But if they die out/damp with time the financial institution seems stable. With this criterion we analyze with the above equations.

Formula (4) shows that if $\mathrm{N}$ increases $\mathrm{P}$ will increase since $\alpha$ is positive constant equation (5) shows $q$ should also increase. $\mathrm{p}_{\mathrm{ccd}}-\mathrm{p}_{\mathrm{ccd} 0}=\mathrm{A}\left(\mathrm{q}-\mathrm{q}_{0}\right)+\mathrm{B}\left(\mathrm{q}-\mathrm{q}_{0}\right)^{2}+\mathrm{C}\left(\mathrm{q}-\mathrm{q}_{0}\right)^{3}+\ldots$ etc. (6)

Now if financial characteristics are such that $q$ reduces $p_{c c d}$ in equation (6) then $\mathrm{P}$ will go on increasing with rise in clients and whole system becomes unstable.

But if the financial characteristics are such that with increase in $\mathrm{p}_{\mathrm{ccd}}$, increase in $\mathrm{q}$ then $\mathrm{P}$ will remain stable. For simplicity considering only A then equation (6) reduces to

$$
\mathrm{p}_{\mathrm{ccd}}-\mathrm{p}_{\mathrm{ccd} 0}=\mathrm{A}\left(\mathrm{q}-\mathrm{q}_{0}\right)
$$

But if $\mathrm{B}$ is also considered with logical reasoning equation (6) becomes

$$
\mathrm{p}_{\mathrm{ccd}}-\mathrm{p}_{\mathrm{ccd} 0}=\mathrm{A}\left(\mathrm{q}-\mathrm{q}_{0}\right)+\mathrm{B}\left(\mathrm{q}-\mathrm{q}_{0}\right)^{2}
$$

Similarly the equation (6b) can alternatively be written as

$$
(\mathrm{r}+\mathrm{A} / 2 \mathrm{~B})^{2}=1 / \mathrm{B}\left(\mathrm{p}_{\mathrm{ccd}}-\mathrm{p}_{\mathrm{ccd} 0}+\left(\mathrm{A}^{2} / 4 \mathrm{~B}\right)\right), \mathrm{r}=\mathrm{q}-\mathrm{q}_{0}
$$




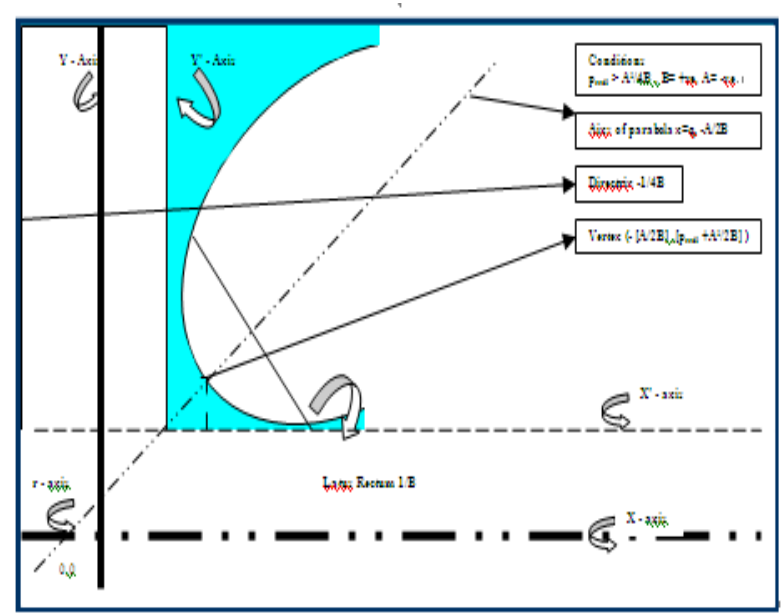

Which represents a parabola with vertex at $\left[-(\mathrm{A} / 2 \mathrm{~B}), \mathrm{p}_{\mathrm{ccd} 0}\right.$ $\left.-\left(A^{2} / 4 B^{2}\right)\right]$ and latus rectum $=1 / B$. If $p_{\operatorname{ccd} 0}>\left(A^{2} / 4 B^{2}\right)$, then vertex of parabola lies above $r$-axis and $B$ being positive, the curve is convex with respect to the r-axis. If B were negative, the curve would be concave with respect to the r-axis in which case credit density would never increase $p_{\text {ccd }} 0$ $\left(\mathrm{A}^{2} / 4 \mathrm{~B}\right)$ a situation not quite plausible. With $\mathrm{B}$ positive and large, $1 / \mathrm{B}$ small thus this results in steeper rise in credit density if $\left(q-q_{0}\right)>-(A / 2 B)$ a phenomena observed normally [5].

This justifies, an action of parameter $B$ on the squared value of $\left(q-q_{0}\right)$ and that of parameter $A$ on $\left(q-q_{0}\right)$ if $A$ is negative $\mathrm{p}_{\mathrm{ccd} 0}>\left(\mathrm{A}^{2} / 4 \mathrm{~B}\right)$ the parabola has vertex in first quadrant. In this case, if $r=\left(q-q_{0}\right)<-(A / 2 B)$, increase in $q$ will decrease credit density in beginning but it will start increasing when $\left(q-q_{0}\right)$ exceeds $(-A / 2 B)$ (for example when $\mathrm{B}$ is large). If $\mathrm{A}>0, \mathrm{r}>0$ would make overall credit rise continuously, the pressure $\mathrm{p}$ in this case would be controlled if there is also continuous increase in banking infrastructure else system becomes unstable. The analysis becomes more involved and can be easily seen from equation 6 that if $\mathrm{C}$ is positive and $\left(\mathrm{q}-\mathrm{q}_{0}\right)>1$ further increase in $\mathrm{q}$ can bring substantial increase in $\mathrm{p}_{c c d}$ but if $\left(q-q_{0}\right)>1$ a small increase in $\mathrm{q}$ might reduce $\mathrm{p}_{\mathrm{ccd}}$.

The interpretation of a state where class differences exist on a wide scale calls for deeper mathematical analysis. In fact to resolve one such plausible relation could be the equation

$$
\mathrm{q}=\mathrm{q}_{0}+\gamma(\mathrm{t}) \mathrm{dP} / \mathrm{dt}+\delta(\mathrm{t}) \mathrm{dp}_{\mathrm{ccd}} / \mathrm{dt}
$$

where $\gamma(\mathrm{t})$ denote $\gamma(\mathrm{t})$ denote change of policy of bank relating credit. $\delta(\mathrm{t})$ is change in creditable surplus to control credit growth. A sufficient mathematical criterion for stability can be obtained by solving equation (5), (6), (7) for stability analysis [6].

\section{STABILITY ANALYSIS}

The equations governing state of financial institution whose stability we wish to examine at time $t$ are given by:

$$
\begin{aligned}
& \mathrm{q}=\mathrm{q}_{0}+\alpha\left(\mathrm{P}-\mathrm{P}_{0}\right) \\
& \mathrm{p}_{\mathrm{ccd}}=\mathrm{p}_{\mathrm{ccd} 0}+\mathrm{A}\left(\mathrm{q}-\mathrm{q}_{0}\right)
\end{aligned}
$$

$$
\mathrm{q}=\mathrm{q}_{0}+\gamma(\mathrm{t}) \mathrm{dP} / \mathrm{dt}+\delta(\mathrm{t}) \mathrm{dp}_{\mathrm{ccd}} \cdot / \mathrm{dt}
$$

where various symbols appearing in the above have their previously defined meaning and it is to be noted that parameter B,C have not been taken into account simplifying the mathematical calculation without sacrificing essence of problem. It is easy to see there exits a unique solution for $\mathrm{q}$ and $p_{\operatorname{ccd} 0}$ at any time $t$ with above system of equations and initial conditions. The conditions under which perturbation introduced at any give time $\mathrm{t}=\mathrm{t}_{1}$ will amplify, die down or come back to its original value with advancement of time and accordingly classify it as unstable, stable or neutral respectively.

Theorem 1: A sufficient condition for stability is that

$$
\lim \int_{\mathrm{t} \rightarrow \infty}^{\mathrm{t}} \mathrm{dt} /\{\gamma(\mathrm{t})+\alpha \mathrm{A} \delta(\mathrm{t})\}=-\infty
$$

Theorem 2: A sufficient condition for instability is that

$$
\lim \int_{t \rightarrow \infty}^{t} d t /\{\gamma(t)+\alpha A \delta(t)\}=+\infty
$$

Theorem 3: A sufficient condition for neutral stability is that

$$
\lim \int_{t \rightarrow \infty \mathrm{t}_{1}}^{\mathrm{t}} \mathrm{dt} /\{\gamma(\mathrm{t})+\alpha \mathrm{A} \delta(\mathrm{t})\}=0
$$

It is easily seen that if $\gamma(\mathrm{t})+\alpha \mathrm{A} \delta(\mathrm{t})>0$ for all $\mathrm{t}, \mathrm{A}>0$ and further that $\gamma(\mathrm{t})+\alpha \mathrm{A} \delta(\mathrm{t})$ is a decreasing function of $\mathrm{t}$, then

$$
\int_{\mathrm{t}_{1}}^{\mathrm{t}} \mathrm{dt} /\{\gamma(\mathrm{t})+\alpha \mathrm{A} \delta(\mathrm{t})\} \rightarrow+\infty \text { as } \mathrm{t} \rightarrow \infty
$$

\section{CONCLUSION}

1) Theorem 1, 2, 3 highlight similar mathematical results and provide the mathematical base for the stability criteria for growth of NPA

2) The above theorems on the other hand may also view movement of operating points along the horizontal and vertical line trading $\mathrm{q}$ with $\mathrm{p}$ where stands for probability of symbol error.

3) Further the NPA growth boundary against which profitability of bank is assured for which similar graphs and mathematical analysis could be generated by the same providing the mathematical proof of the above.

4)

\section{REFERENCES}

[1] Master Circular on Income Recognition, Asset Classification, Provisioning \& Other Related Matters - UCBs, RBI/2009-10/93 UBD.PCB.MC.No. 3 / 09.14.000 / 2009-10

[2] .http://www.rbi.org.in/scripts/NotificationUser.aspx?Mode=0\&Id=51 54

[3] Guidelines on purchase/sale of Non Performing Assets, RBI/2005-06/54, DBOD.NO.BP. BC. 16 / 21.04.048/ 2005-06 www.rbi.org.in/scripts/BS_CircularIndexDisplay.aspx? Id $=2372-34 \mathrm{k}$ 5. 
[4] Prashanth K Reddy "A comparative study of Non Performing Assets in India in the Global context - similarities and dissimilarities, remedial measures", October 2002, The Indian Institute of Management Ahmedabad, India.

[5] Steven Radelet and Jeffrey Sachs, "The Onset of the East Asian Financial Crisis", Harvard Institute for International Development, March 30, 1998.

[6] Shannon's Principle of Information Capacity Theorem.

[7] Gaurav Bajpai "shortest congestion path algorithm based on quality of service" International conference on computing, communication and control technologies. (CCCT'04).

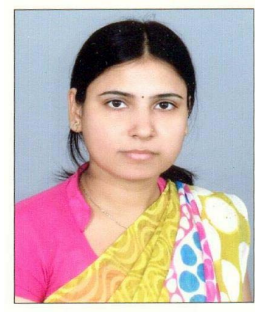

Jaya Shukla completed her B.A. in 1998, M.A. in 2000 and is currently pursuing her Ph.D. from Lucknow University, Lucknow, India. ${ }^{1}$ her research interest includes non performing assets and related fields she has some publications to her credit.

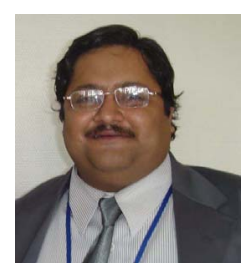

Gaurav Bajpai received the B.Tech. degree in Computer Science \& Engineering from SRMSCET Rohilkhand University, India in 2000, M.Tech. degree in Software Engineering from Motilal Nehru National Institute of Technology, Allahabad, India and Ph.D. degree from Uttar Pradesh Technical University, Lucknow, India in 2006. He was an assistant Professor in the Department of Computer Science and Business Administration, Academy of Medical Sciences and Technology, Khartoum, Sudan from April 2006 to March 2007. Since March 2007, he is working as a Senior Lecturer in the Department of Computer Engineering and Information Technology, Faculty of Engineering, Kigali Institute of Science and Technology, Rwanda. His research interests include software engineering, network routing, network hardware security and bio-medical engineering. He has published more than 35 International Journal and conference papers. 